\title{
Production and applications of crude polyhydroxyalkanoate- containing bioplastic from the organic fraction of municipal solid waste
}

\author{
V. Ivanov $\cdot$ V. Stabnikov $\cdot$ Z. Ahmed \\ S. Dobrenko $\cdot$ A. Saliuk
}

Received: 26 April 2013/Revised: 3 December 2013/ Accepted: 11 January 2014/Published online: 4 February 2014

(C) Islamic Azad University (IAU) 2014

\begin{abstract}
A considerable economic and environmental need exists for the further development of degradable plastic polyhydroxyalkanoates (PHAs), which are produced by bacteria. However, the production cost of this bioplastic, manufactured using conventional technologies, is several times higher than that of petrochemical-based plastics. This is a major obstacle for the industrial production of PHA bioplastic for non-medical use. The aim of this review is to evaluate suitable methods for the significant reduction in bioplastic production costs. The study findings are as follows: (1) The organic fraction of municipal solid waste can be used as a raw material through acidogenic fermentation; (2) non-aseptic cultivation using mixed bacterial culture can significantly reduce the production cost; (3) biotechnology of bacterial cultivation should ensure selection of PHA-accumulating strains; (4) applications of PHA-
\end{abstract}

V. Ivanov ( $₫)$

Department of Civil, Construction and Environmental Engineering, Iowa State University, Ames, IA 50011, USA

e-mail: vivanov@iastate.edu

V. Stabnikov

Department of Biotechnology and Microbiology, National

University of Food Technologies, Kiev 01601, Ukraine

Z. Ahmed

Department of Civil Engineering, King Abdulaziz University, Jeddah, Kingdom of Saudi Arabia

S. Dobrenko

ASA College, Brooklyn, NY 11201, USA

A. Saliuk

Department of Biochemistry and Ecological Control, National University of Food Technologies, Kiev 01601, Ukraine containing material in both construction industry and agriculture do not require expensive extraction of PHAs from bacterial biomass. The implementation of the above findings in the current manufacturing process of PHAcontaining bioplastic would significantly reduce production costs, thereby rendering PHA-containing bioplastic an economically viable and environmentally friendly alternative to petrochemical-based plastics.

Keywords Bioplastic - Polyhydroxyalkanoates . Municipal solid waste $\cdot$ Construction material

\section{Biodegradable plastics}

Biodegradable plastic

Quantity of plastics in municipal solid waste (MSW) in USA is 27 million tons (US EPA 2011). The major portion of these materials is incinerated or landfilled, which both are not-sustainable and environmentally not-friendly solutions. A considerable economic and environmental need exists for the further development of biodegradable plastics that will be transformed to carbon dioxide and water being landfilled or disposed in the environment. Additional advantage of biodegradable plastics is that many of them are produced biologically from renewable sources so the production of these bioplastics will increase environmental and economic sustainability. However, the production cost of the bioplastics, manufactured using conventional technologies, is several times higher than that of petrochemical-based plastics. Therefore, reduction in the bioplastic production cost due to the usage of cheap raw materials and technological innovations is essential for the bioplastic production and applications. 
Chemical and physical properties of PHAs

One available type of bioplastics is polyhydroxyalkanoates (PHAs) that are polyesters accumulated in bacterial biomass as the storage compounds. After accumulation, these substances can be used by a cell as the intracellular carbon and energy sources. It is known that PHAs are accumulated under excess of carbon and energy sources and limitation of growth by low concentrations of oxygen and the sources of nitrogen, phosphorus, and other elements that are used for biomass synthesis. Most important PHA polymers are poly-3-hydroxybutyrate (PHB) with monomer formula $\left(-\mathrm{OCH}\left(\mathrm{CH}_{3}\right)-\mathrm{CH}_{2}-\mathrm{C}(\mathrm{O})-\right)$ and polyhydroxyvalerate (PHV) with monomer formula $\left(-\mathrm{OCH}\left(\mathrm{CH}_{2} \mathrm{CH}_{3}\right)-\mathrm{CH}_{2}-\mathrm{C}(\mathrm{O})-\right)$. PHAs are accumulated in the form of the granules inside cells of many bacterial species.

Content of accumulated PHAs can be up to $80 \%$ of dry biomass. These substances can be extracted from bacterial biomass and used in practice as a plastic with the melting temperature $160-180{ }^{\circ} \mathrm{C}$, tensile strength $24-40 \mathrm{MPa}$, and elongation at break 3-142\%. Lastly, elasticity of the PHA plastic depends on the content of PHV in PHAs. These properties are comparable with the properties of petroleum-based thermoplastics. The most common commercial PHAs consist of a copolymer PHB and PHV together with a plasticizer/softener and inorganic additives such as titanium dioxide and calcium carbonate. Chemical and physical properties of PHAs are described in the reviews and monographies (Volova 2004; Lenz and Marchessault 2005; Castilho et al. 2009; Sudesh and Abe 2010; Sudesh 2013).

\section{Problems of PHA production}

The production of biodegradable PHA-containing bioplastic can provide many benefits to the industry and to the environment. However, known technologies of PHA production have three essential disadvantages:

- use of aseptic culture of selected or genetically modified strains that require high expenses for the sterilization of equipment and medium, as well as for the maintenance of aseptic conditions during biosynthesis of bioplastic;

- use of relatively expensive nutrients such as pure mineral salts and pure (defined) sources of carbon and energy;

- use of expensive, often flammable and toxic organic solvents and/or energy- and reagent-consuming methods for the extraction of PHAs from bacterial cells.

The aim of this paper is to analyze the feasibility of low-cost PHA-containing bioplastic production and applications.
Nutrients for non-aseptic bioplastic production

Effect of nutrients excess or shortage for microbial growth

Many wild strains of bacteria can accumulate PHAs under excess carbon and energy, while growth is limited to such essential nutrients as $\mathrm{O}_{2}$ (electron acceptor), $\mathrm{N}, \mathrm{P}, \mathrm{Mg}, \mathrm{K}$, or S. Meanwhile, there are a lot of mutant or recombinant strains that do not require nutrient limitations for accumulation of PHAs (Ben Rebah et al. 2004). Growth limitation also affects stability of accumulated PHAs. For example, Alcaligenes eutrophus can accumulate PHAs up to $80 \%$ of dry biomass under excess of carbon source and limitation by $\mathrm{P}$ or $\mathrm{N}$, but this stock is oxidized after addition of P or N (Ben Rebah et al. 2004).

Use of carbohydrates for PHA production

Mono- and disaccharides are transformed under growth limitation by other nutrients preferably either to the extracellular and intracellular polysaccharides in prokaryotes or to the intracellular polysaccharides and lipids in eukaryotes (Ivanov 2010). Cheap sources of mono- and disaccharides for PHA production are such food-processing wastes as molasses and whey (Du et al. 2012). Starch-containing agricultural or food-processing wastes could also be used after chemical or enzymatic hydrolysis of starch.

Monosaccharides for PHA synthesis can be produced from lignocellulosic materials to reduce the cost of raw materials. Different agricultural wastes can be used for this purpose through chemical or enzymatic hydrolysis (Du et al. 2012; Sandhya et al. 2013). Mono- and disaccharides can be used for the production of PHAs mainly in aseptic cultivation because it is possible to select strains of bacteria (Du et al. 2012; Vishnuvardhan and Thirumala 2012; Yee et al. 2012) or yeasts (Abd-El-Haleem et al. 2007) with low production of storage carbohydrates under excess of carbon and energy source. Meanwhile, the wild strains of microorganisms in non-aseptic mixed culture will transform excess of external sugars to the glycogen, exopolysaccharides, or lipids (Ivanov 2010). Therefore, excess of carbon and energy source and growth limitation by other nutrients in non-aseptic mixed culture could lead to the growth of either glycogen-accumulating and slime-producing bacteria, or lipid- and glycogen-accumulating yeasts and mycelial fungi.

Use of organic acids for PHA production

The problem with accumulation of polysaccharides or lipids under excess of carbon and energy source can be easily overcome by acidification of medium containing a mixture of volatile fatty acids (VFAs) that are readily 
Biopolymers

(polysaccharides, proteins, nucleic acids)

Hydrolytic bacteria

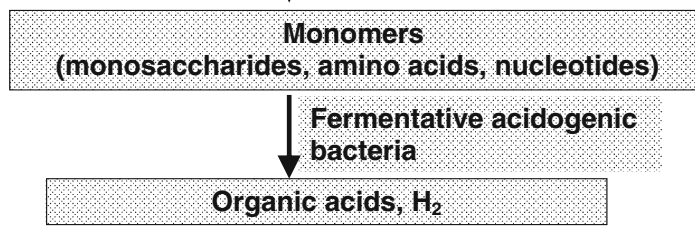

Fig. 1 Microbial groups and substances of acidogenic fermentation

converted to PHAs. Organic acids, if they are sole carbon and energy source for the growth of bacteria, are accumulating preferably as the PHA storage compounds. Therefore, organic acids must be used for non-aseptic cultivation of mixed culture to ensure selective conditions for the growth of PHA-accumulating bacteria. In the case when carbohydrates of organic waste are the major sources of carbon and energy, these components should be converted to organic acids for the cultivation of PHA-accumulating bacteria under non-aseptic conditions.

Enzymatic hydrolysis of polysaccharides coupled with anaerobic acidogenic fermentation of hydrolysis products is the most acceptable bioprocess for this transformation (Fig. 1). There are many bacterial species that are able to hydrolyze polysaccharides, including cellulose and hemicellulose, and then to ferment them to organic acids, hydrogen, and carbon dioxide as the end products. The species of microorganisms participating in these processes depend on the sources of carbon and energy. For example, the representatives of genera Clostridium, Ruminococcus, Butyrivibrio, Acetivibrio, Fibrobacter, Eubacterium, and Bacteroides are usually dominating in the microbial community during acidogenic fermentation of cellulose (Lynd et al. 2002). Most typical material balance of this process can be shown by the following equation of acidogenic fermentation in the rumen (molar ratios of VFAs were taken from Madigan et al. 2012):

$$
\begin{aligned}
\mathrm{C}_{6} \mathrm{H}_{12} \mathrm{O}_{6}+0.82 \mathrm{H}_{2} \mathrm{O} \rightarrow & 1.13 \mathrm{CH}_{3} \mathrm{COOH} \\
& +0.35 \mathrm{C}_{2} \mathrm{H}_{5} \mathrm{COOH} \\
& +0.26 \mathrm{C}_{3} \mathrm{H}_{7} \mathrm{COOH} \\
& +1.67 \mathrm{CO}_{2}+2.47 \mathrm{H}_{2}
\end{aligned}
$$

where $\mathrm{C}_{6} \mathrm{H}_{12} \mathrm{O}_{6}$ is a monomer of cellulose and $\mathrm{CH}_{3} \mathrm{COOH}$, $\mathrm{C}_{2} \mathrm{H}_{5} \mathrm{COOH}$, and $\mathrm{C}_{3} \mathrm{H}_{7} \mathrm{COOH}$ are acetic, propionic, and butyric acids, respectively.

Multistage transformation of the carbon and energy sources to PHAs

Biotransformation of carbohydrates to VFA and hydrogen through the acidogenic fermentation is the most suitable process in the utilization of MSW organic fraction for PHA production. Different substances in MSW organic fraction can be transformed to VFA, which are selective and the most favorable substances for the biosynthesis of PHAs under non-aseptic conditions. In this case, MSW organic fraction can be converted to PHAs using two-stage system that includes the production of organic acids through the acidogenic fermentation of carbohydrates and the biosynthesis of PHAs from these organic acids (Yu 2006). Different organic acids and polyols added to the medium can be used by cells for copolymerization and enhancement of the PHA synthesis. For example, even small concentration of caproic acid in medium significantly increased the percentage of PHAs in bacterial biomass.

The system could contain two separate bioreactors, in order to satisfy the different physiologies and metabolic activities of the two types of microbes. First bioreactor is used for acidogenesis of organic waste, and a second one is used for the cultivation of a mixed culture of PHA-producing bacteria. The organic acids should preferably be transferred from the first bioreactor to the second bioreactor without causing a solid mixing between these two bioreactors. VFA can be transferred through membrane into the second bioreactor where the organic acids will be utilized by bacteria to produce PHAs. However, in the case when different organic wastes are used for fermentation, the remaining organic dissolved substances and particles can reduce the quality of produced PHAs. To solve this problem, it could be better to extract all volatile organic compounds and hydrogen from the acidogenic bioreactor using recycling of biogas with absorption of VFA and using these VFA in the second bioreactor.

Use of hydrogen for PHA accumulation

The use of hydrogen for the production of PHAs is well known (Choi et al. 2010; Volova 2004). For example, a process for converting organic materials, such as organic wastes, into bioplastic through thermal gasification of the organic material into carbon monoxide and hydrogen was proposed, followed by photosynthetic bacterial assimilation of the gases into cell material under anaerobic conditions (Maness and Weaver 1994). Some bacteria can transform gaseous hydrogen and carbon monoxide into PHAs (Choi et al. 2010; Volova 2004). It is possible to perform acidogenic fermentation with sufficient yield of hydrogen (Braun et al. 2010) that will be used for the production of bioplastic. However, hydrogen-oxidizing bacteria cannot utilize simultaneously with hydrogen the wide range of organic compounds for the accumulation of PHAs. So, hydrogen produced during acidogenic fermentation of organic wastes could be the useful source for PHA 
production but has to be used altogether with VFA produced from organic wastes.

Use of non-carbohydrates for PHA accumulation

Agricultural, food-processing, or biofuel production wastes containing palm oil (Gumel et al. 2012; Md Din et al. 2013; Sudesh 2013), seeds (Preethi et al. 2012), fats and waste cooking oil, as well as glycerol after fat hydrolysis (Du et al. 2012) or biodiesel production (Palmeri et al. 2012) can be used for the low-cost production of PHAs either from long-chain fatty acids and glycerol after chemical hydrolysis pretreatment or due to direct biotransformation of triacylglycerides (Du et al. 2012).

The sources of inorganic nutrients

The sources of $\mathrm{N}, \mathrm{P}, \mathrm{S}, \mathrm{Fe}$, and microelements can be also supplied as the components of organic wastes. The ratio of the major inorganic nutrients and the sources of $\mathrm{N}$ and $\mathrm{P}$ to organic carbon should be in the range from 75:5:1 to 125:5:1 (Braun et al. 2010). Typical C:N:P ratio for anaerobic acidogenic fermentation is 100:5:1. Nitrogen could be assimilated from amines, nitrates, and ammonium. Phosphorus is usually supplied from nucleotides and orthophosphates. Suitable sources of inorganic nutrients could be reject water of municipal wastewater treatment plants (see below) and the mixtures of food-processing and agricultural wastes containing $\mathrm{N}, \mathrm{P}, \mathrm{S}, \mathrm{Fe}$, and microelements. However, cost of mineral components is a small contribution to the overall cost of PHA production. The most important factor is a cost of carbon and energy source(s), which could be the organic fraction of MSW.

\section{Municipal solid waste for bioplastic production by mixed culture}

MSW as a resource for PHA production

Proper management of MSW is an important environmental and economic problem. Approximately 250 million tons of MSWs are generated in USA and only 85 million tons of these materials are recycled or composted (US EPA 2011). The majority of MSW, $55 \%$, is deposited in landfills, and about $13 \%$ is incinerated (Barlaz et al. 2010). Landfills are a significant source of greenhouse gas emissions and require a lot of land. Incineration of MSW generates air pollutants and a lot of ash, which is requiring landfilling as hazardous waste.

Such components of MSW as paper and paperboard (16.2\% of MSW in USA), wood (8.2\% of MSW in USA), yard trimmings (8.6 \% of MSW in USA), and food scraps
(20.5\% in MSW in USA) contain biodegradable organic matter (US EPA 2011). So, about $53 \%$ of MSW can be used for biotransformation to value-added products instead of landfilling or incineration. Ideally, all this organic matter can be utilized (Dobrenko and Joarder 2011).

\section{Extraction of the organic fraction from MSW}

An effective way to avoid the construction of new incineration plants and reduce area of landfills is shredding of MSW following the automatic hydroextraction and hydroseparation of shredded MSW, and then the conversion of the different fractions to value-added products (Dobrenko et al. 2012; Rahman et al. 2013). The extraction of small particles of the organic fraction of MSW using hydroseparation is more effective process than aeroseparation of MSW particles and could be effectively used after recovery of dry components using aeroseparation (Dobrenko et al. 2012). Cost-efficient waste-to-resource technological solution, especially for the coastal areas, could be automated seawater-based separation of MSW with the production of settled fraction (stones, metals, glass, and rigid plastic), floated fraction (plastics), and suspended fraction (dissolved and suspended biodegradable organics), all of which could be transformed to value-added products. To cutoff the expenses for freshwater, separation of MSW in the coastal areas could be performed using gravitational separation in seawater with the production of three fractions: floated fraction (plastics), settled fraction (stones, metals, glass, and rigid plastic), and suspended fraction, which is represented by dissolved and suspended biodegradable organics (Cesaro et al. 2011).

The methods of biotransformation of the organic fraction of MSW

The organic fraction of MSW is commonly planned to be used for anaerobic digestion that is producing methane for heating or generation of electricity (Kelleher 2007). Organic wastes can generate methane in quantity from 60 to $220 \mathrm{~L}$ of methane $/ \mathrm{kg}$ of dry waste when the content of anaerobically biodegradable components such as cellulose, hemicellulose, and starch changed from 55 to $95 \%$. This function is shown in Fig. 2, which is plotted using data from Barlaz et al. (2010). There is approximately $0.11 \mathrm{~kg}$ of organic carbon per dry kilogram of MSW (Barlaz et al. 2010), so the content of biodegradable carbohydrates is $0.11 \times 30 / 12=0.275 \mathrm{~kg} / \mathrm{kg}$ of dry MSW. The problem of methane production from MSW is that methanogens are very sensitive to many components of water-extractable fraction of MSW such as heavy metals, pesticides, surfactants, ammonium, oils, fats, and sulfates (Ivanov et al. 2002; O'Flaherty et al. 2010; Mudhoo and Kumar 2013). 


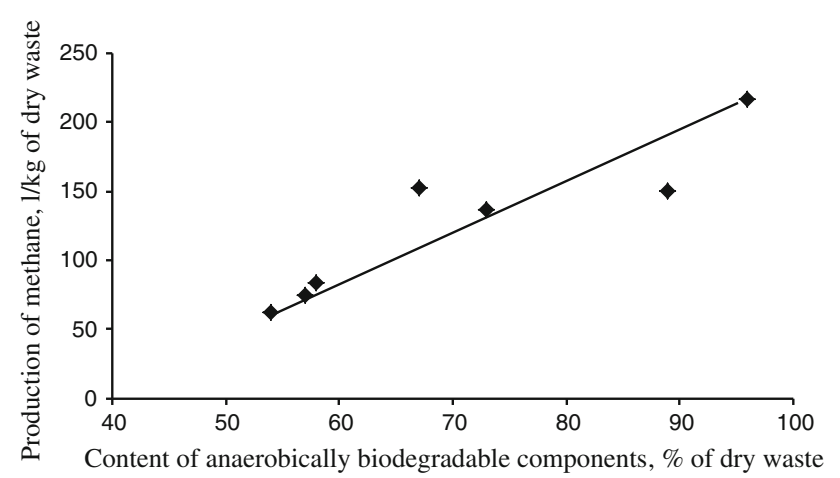

Fig. 2 Production of methane $(Y \mathrm{~L} / \mathrm{kg}$ of dry waste) as function of the content of anaerobically biodegradable components ( $X \%$ of dry waste) such as cellulose, hemicellulose, and starch. $Y=3.1 X+92$ $\left(R^{2}=0.84\right)$

Additionally, cellulose, hemicellulose, and starch are dominating compounds in the organic fraction of MSW. Therefore, methanogenesis from this fraction will be inhibited without $\mathrm{pH}$ control because the major products of anaerobic digestion of these compounds are organic acids decreasing $\mathrm{pH}$ to about 5 , whereas optimum $\mathrm{pH}$ for majority of methanogens is about 7 . That is why optimal biotransformation of the organic fraction of MSW could not be the production of methane but other value-added products. These products, as shown in this paper, could be crude PHA-containing bioplastic or biocement. In this case, the organic fraction of MSW is used for acidogenic fermentation to produce VFA and hydrogen for PHA synthesis accompanying with the formation of dissolved calcium salts that could be used for the biocementation (Ivanov 2010).

Productivity of acidogenic fermentation of MSW organic fraction

The representatives of bacterial genera such as Acetobacter, Bacteroides, Clostridium, Citrobacter, Enterobacter, Moorella, Propionibacterium, Ruminococcus, Thermoanaerobium, and many others are participating in acidogenic fermentation. Anaerobic conditions must be maintained so that an oxidation/reduction potential should be from -50 to $-400 \mathrm{mV}$, and the $\mathrm{pH}$ should be in the range from 5.5 to 8 . The content of the final products of acidogenic fermentation depends mainly on the content of raw materials and $\mathrm{pH}$. For example, after batch acidogenic fermentation of maize silage in a solid-state fermentation reactor with percolation, the total VFA concentration was $11.24 \mathrm{~g} / \mathrm{L}$, consisting of $3.34 \mathrm{~g} / \mathrm{L}$ acetic acid, $0.28 \mathrm{~g} / \mathrm{L}$ propionic acid, $0.36 \mathrm{~g} / \mathrm{L}$ isobutyric acid, $3.98 \mathrm{~g} / \mathrm{L} n$-butyric acid, $0.11 \mathrm{~g} / \mathrm{L}$ isovaleric acid, $0.24 \mathrm{~g} / \mathrm{L} n$-valeric acid, $2.77 \mathrm{~g} / \mathrm{L}$ caproic acid, and $0.18 \mathrm{~g} / \mathrm{L}$ lactic acid. Produced gas contained
$35.2 \%$ of hydrogen and $68.8 \%$ of carbon dioxide (Strauber et al. 2012).

The yield of VFA in grams of chemical oxygen demand (COD) per grams of volatile solids (VS = approximately $g$ of organic matter) from of source-sorted organic MSWs was $0.27 \mathrm{~g} \mathrm{COD} / \mathrm{g}$ VS at psychrophilic conditions $\left(14-22{ }^{\circ} \mathrm{C}\right)$ and $0.5-0.9 \mathrm{~g} \mathrm{COD} / \mathrm{g}$ TVS at mesophilic $\left(25-30{ }^{\circ} \mathrm{C}\right)$ and thermophilic conditions $\left(45-55{ }^{\circ} \mathrm{C}\right)$. VFA could reach $15 \%$ of the soluble COD at psychrophilic conditions and the hydraulic retention time (HRT) 4-4.5 days and $90 \%$ of soluble COD at mesophilic conditions and HRT 1-2 days in the continuously stirred tank reactor (Bolzonella et al. 2005). The organic loading rate for the anaerobic acidogenic reactor fermenting the organic fraction of municipal solid wastes (OFMSW) could be between 20 and $90 \mathrm{~kg}$ of organics $/ \mathrm{m}^{3} /$ day with the firstorder kinetic constant $\left(K_{\mathrm{h}}\right)$ for hydrolysis of solid organic wastes about 0.1-0.5 1/day (Bolzonella et al. 2005).

The requested HRT to achieve a given final concentration of fed substrate is $\left(S_{0}-S\right) / S K_{\mathrm{h}}$, where $S_{0}$ is the concentration of the influent substrate (as COD), $g / L ; S$ is the concentration of the effluent substrate (as COD), $\mathrm{g} / \mathrm{L}$; and $K_{\mathrm{h}}$ is the first-order reaction constant, $1 /$ day. So the volume of the anaerobic reactor for digestion of OFMSW from a population of 100,000 inhabitants, produced $200 \mathrm{~g}$ organic wastes/inhabitant/day, has to be about $40-65 \mathrm{~m}^{3}$ (Bolzonella et al. 2005). Therefore, anaerobic digestion of the organic fraction of MSW to organic acids and hydrogen can be effectively used to produce nutrients for the production of PHA-containing bioplastic.

Production of PHAs based on the use of seawater

Water-saving process could be shredding of MSW, separation of the organic fraction of MSW, and performance of acidogenic fermentation in seawater. The complication of anaerobic acidogenic fermentation of the organic fraction of MSW in seawater is sulfate bioreduction that produces toxic, corrosive, and bad-smelling dihydrogen sulfide:

$\mathrm{CH}_{3} \mathrm{COOH}+\mathrm{SO}_{4}^{2-} \rightarrow 2 \mathrm{CO}_{2}+\mathrm{H}_{2} \mathrm{~S}+2 \mathrm{OH}^{-}$.

It could be possible to diminish sulfate reduction using $\mathrm{Fe}$ (III) compounds such as iron ore to stimulate iron bioreduction that is competing with sulfate bioreduction (Stabnikov and Ivanov 2006):

$\mathrm{CH}_{3} \mathrm{COOH}+8 \mathrm{Fe}^{3+}+2 \mathrm{H}_{2} \mathrm{O} \rightarrow 2 \mathrm{CO}_{2}+8 \mathrm{Fe}^{2+}+8 \mathrm{H}^{+}$.

Halophilic bacteria, which can grow in concentrated seawater, have such advantage that intracellular PHA granules can be isolated by cost-effective osmotic cell lysis using distilled or freshwater. This process can significantly 
reduce the cost of PHA extraction from bacterial biomass (Selvakumar et al. 2011).

$\mathrm{pH}$ maintenance in acidogenic fermentation

$\mathrm{pH}$ is dropped during acidogenic fermentation due to increase in the concentrations of organic acids. Production of VFA could be at the level of $0.1 \mathrm{~g} / \mathrm{g}$ of refuse (Barlaz et al. 2010). So, considering that content of organic matter is about $0.275 \mathrm{~g} / \mathrm{g}$ of dry MSW (see data above), the production of VFA could be about $0.37 \mathrm{~g} \mathrm{VFA} / \mathrm{g}$ of dry organic fraction of MSW. The microbial communities of acidogenic fermentation are active at the high concentrations of organic acids, for example at least at 20, 5, and $15 \mathrm{~g} / \mathrm{L}$ of acetate, butyrate, and propionate, respectively (Wang et al. 1997). The $\mathrm{pH}$ of the organic fraction of municipal waste can drop below 5.5 during acidogenic fermentation (Barlaz et al. 2010); meanwhile, optimal pH for acidogens is above 6.0. There are several ways to maintain optimal $\mathrm{pH}$ during acidogenic fermentation of organic wastes:

1. For fast and effective acidogenic fermentation, the $\mathrm{pH}$ must be controlled automatically by measuring and titrating if necessary with alkali $(\mathrm{NaOH})$. However, it will require a lot of chemical reagent and the system of $\mathrm{pH}$ control, so the cost of products could be higher than the acceptable value.

2. The digestibility of carbohydrate-rich wastes can be improved by codigestion with the wastes containing high amount of proteins (Macias-Corral et al. 2008). The mixing of carbohydrate- and protein-containing waste maintains $\mathrm{pH}$ due to neutralization of protons released during anaerobic digestion of carbohydrates by hydroxide ions released during ammonification of protein and hydrolysis of ammonium.

3. Third method, shown in Fig. 3a, is an addition of the fine powder of limestone $\left(\mathrm{CaCO}_{3}\right)$ or dolomite $\left(\mathrm{CaMgCO}_{3}\right)$. In this case, there will be two fractions at the end of acidogenic fermentation: dissolved salts of organic acids that can be used for biosynthesis of bioplastic and semisolid residual containing $\mathrm{Ca}$ and $\mathrm{Mg}$ salts that can be used for the ground strengthening and reduction in soil permeability in the road, dams, ponds, and channel constructions or for soil erosion control (Ivanov and Chu 2008; Ivanov 2010).

4. Fourth method is the removal of VFA from the reactor for acidogenic fermentation using recycling of biogas, containing $\mathrm{CO}_{2}$ and $\mathrm{H}_{2}$, and absorption of VFA from biogas using alkaline solution (Figs. 3b, 5). This recycle of biogas ensures $\mathrm{pH}$ maintenance and high mass transfer of VFA from the acidogenic bioreactor to the tank for VFA collection and storage. Similar in principle, system of biogas recycling was used for the removal of ammonia from the reactor for methanogenic fermentation (Lei et al. 2007; Abouelenien et al. 2010).

\section{Batch and continuous biosynthesis of bioplastic by mixed culture}

Non-aseptic cultivation for the production of PHAs

Aseptic cultivation of selected or recombinant strain of bacteria requires thermal sterilization of materials and equipment. Cost of aseptic cultivation is several times higher than cost of non-aseptic cultivation. Therefore, nonaseptic cultivation of mixed microbial culture, which is able to accumulate PHAs in biomass, could be low-cost technology for industrial production of PHAs. The major points of using a mixed bacterial culture for PHA production were considered in several patents, reviews, and papers and are shown below: (a) Activated sludge, a wellknown mixed culture, is able to store PHAs as the carbon and energy storage material under unsteady conditions arising from an intermittent feeding regime and variation in the presence of an electron acceptor; (b) activated sludge accumulates PHAs to around $20 \%$ of dry weight under anaerobic conditions, but the content can be increased to $62 \%$ in a microaerophilic-aerobic sludge process. Activated sludge for the production of PHAs can be from municipal wastewater treatment plant (Mokhtarani et al. 2012) or from food industrial wastewater treatment process (Buathong et al. 2012). In the last case, PHA production and accumulation in activated sludge added with acetate were $1 \mathrm{~g} / \mathrm{L}$ and consisted $49 \%$ of dry sludge weight. Oxygen management is crucial for the process because excessive aeration rate allows high biomass growth yield but decreases PHA yield; (c) the content of accumulated PHAs in a mixed culture is usually lower that in a pure culture, which can accumulate PHAs up to $80 \%$ of cell dry weight. However, the merits of the PHA production in a mixed culture are an enhanced economy, a simpler process control, no requirement of aseptic processing, and use of wastes.

PHA-accumulating organisms

PHA-producing mixed culture will comprise representatives of the genera Acinetobacter, Alcaligenes, Alcanivorax, Azotobacter, Bacillus, Burkholderia, Delftia, Klebsiella, 
Fig. 3 pH maintenance in acidogenesis through fermentation with limestone/ dolomite (a) or recycle of biogas with adsorption of VFA (b)

\section{A}

Rotating acidogenic reactor

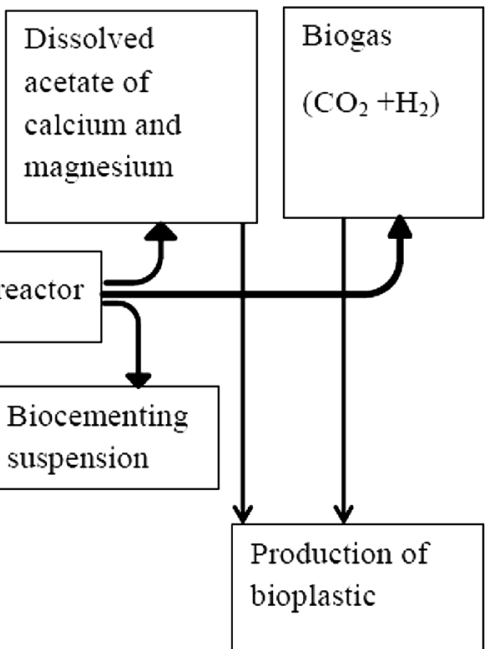

\section{B}

Cellulosecontaining waste

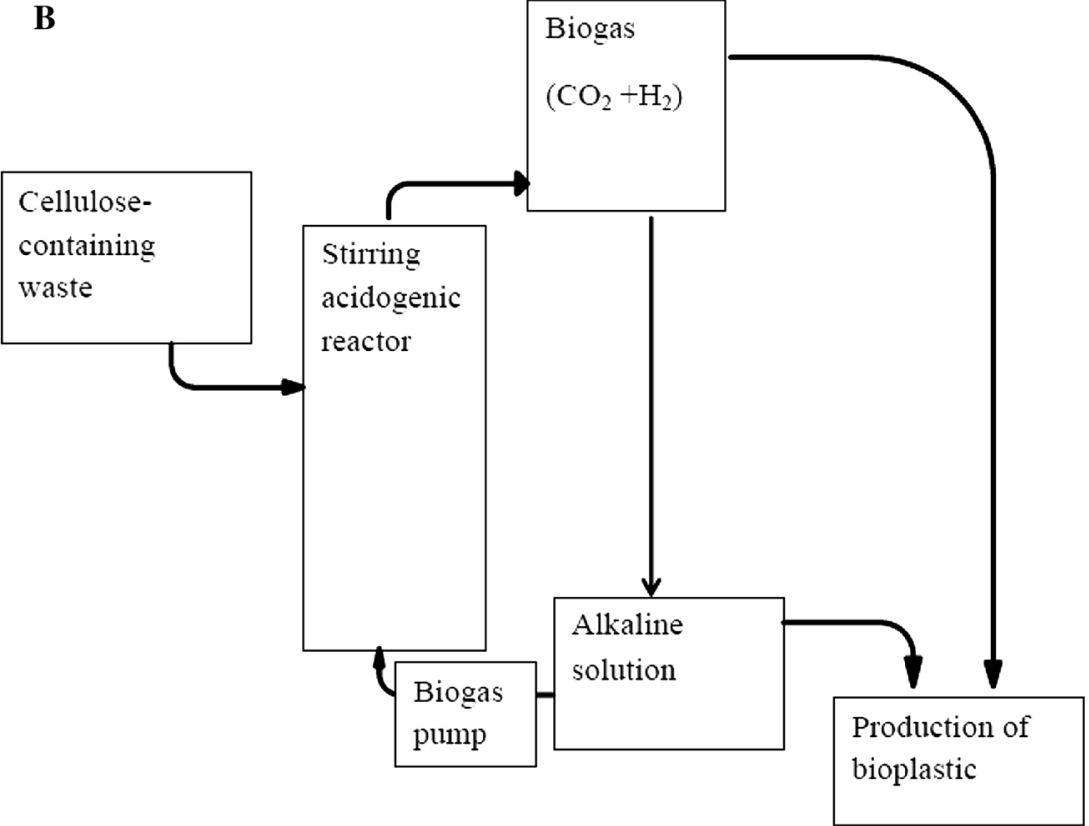

Marinobacter, Pseudomonas, Ralstonia, Rhizobium, and many others. Initial inoculation can be made using aerobic forest or garden soil suspension or activated sludge of MWWTP. Accumulation of PHAs by mixed microbial cultures occurs usually under transient conditions of carbon and energy sources, known, respectively, as an aerobic dynamic feeding and anaerobic/aerobic process. In these processes, PHA-accumulating organisms, which are quite diverse in terms of phenotype, are selected by the dynamic operating conditions imposed to the bioreactor. The stability of these processes during longtime operation and the similarity of the polymer physical/chemical properties to the one produced by pure cultures were demonstrated. The accumulation of PHAs in a mixed culture can be implemented at industrial scale (Salehizadeh and Van Loosdrecht 2004; Serafim et al. 2008).

Continuous selection of PHA-accumulating bacteria

The following process can be used for the production of PHA-containing bioplastic from the organic raw materials and wastes. This production method includes supply of cheap and essential raw materials and synthesis of PHAs under non-aseptic conditions, which can effectively reduce the cost of bacterial cultivation because there will be no need to sterilize medium, air, and reactors. This process includes the following stages: 
Fig. 4 Preparation of nutrients for bioplastic production from waste

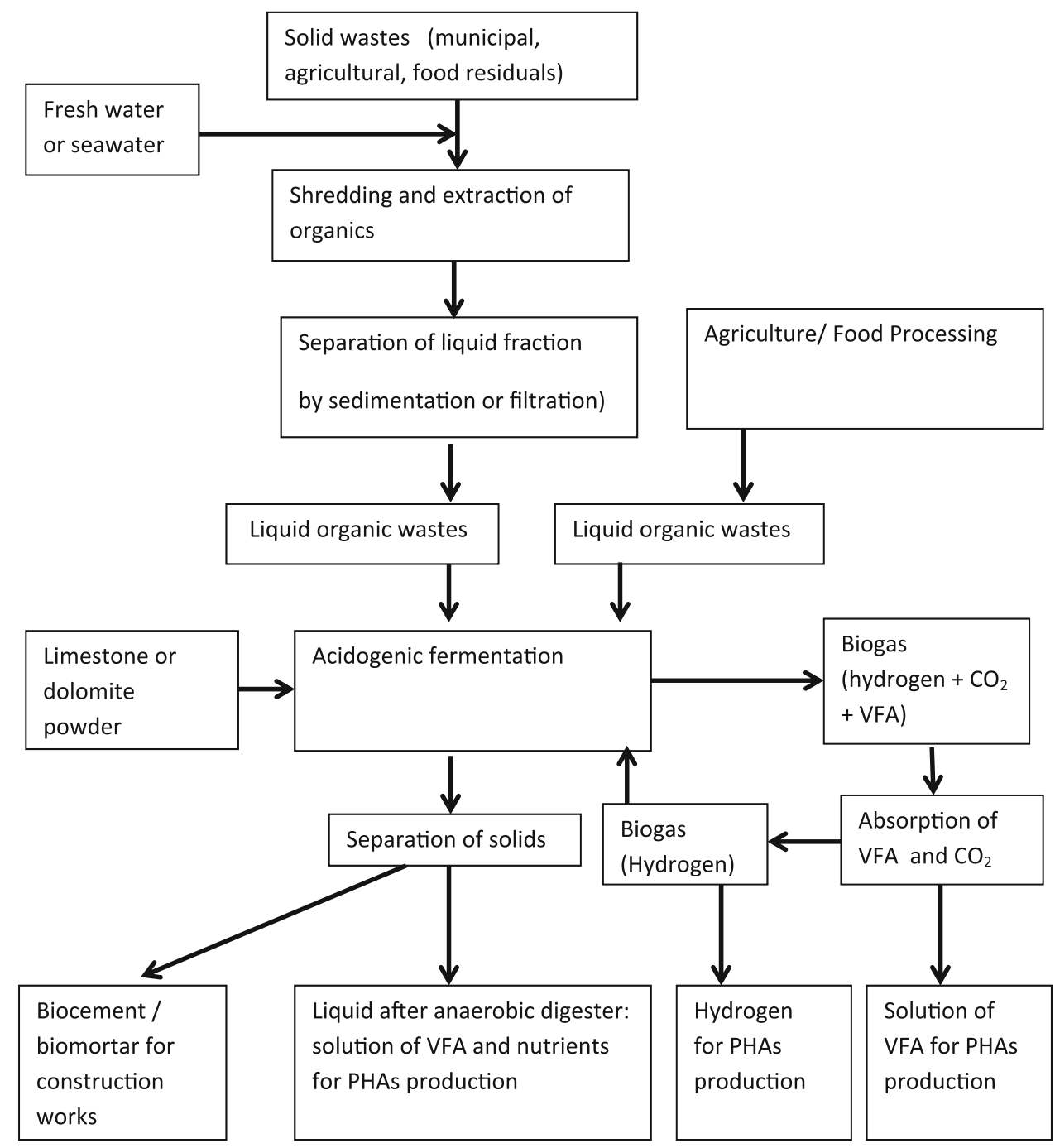

1. production of VFA from acidogenic fermentation of MSW organic fraction with addition of the limestone/ dolomite to maintain the neutral $\mathrm{pH}$ in the anaerobic reactor (Fig. 4);

2. separation of the liquid fraction after the anaerobic digester;

3. continuous separation of VFA and hydrogen from the anaerobic digester, extraction, and use of VFA (Fig. 4);

4. PHA accumulation comprising the combination of the selection and cultivation steps, which include cultivation of PHA-producing microbes in a cultivation reactor and feeding PHA-producing microbes into a selection reactor.

5. extraction of PHAs comprising the step of degradation of microbial cells into PHA granules and cell debris, and the step of separation of the PHA granules from the cell debris.
A continuous process can be used not only because of higher productivity but also because it can be used for permanent selection and maintenance of a culture with the highest productivity of PHAs synthesis. In every mixed culture, for example, in biological wastewater treatment, the desired selection of bacterial strains is ensured by the retention, recycling, or transfer of some microbial groups between different reactors (Gray 2004; Ivanov 2010). That is why the PHA production continuous process should comprise the combination of the stages for the selection of PHA-accumulating bacteria, cultivation of bacterial biomass, and PHA-accumulating stages with the recycling loop of PHA-accumulating cells as shown in Fig. 5. The selector could be a bioreactor with intensive aeration but without supply of nutrients so cells with intracellular storage of carbon and energy will have selective advantages for growth. This advantage will depend on the retention time in the bioreactor selector. There must be sufficient 


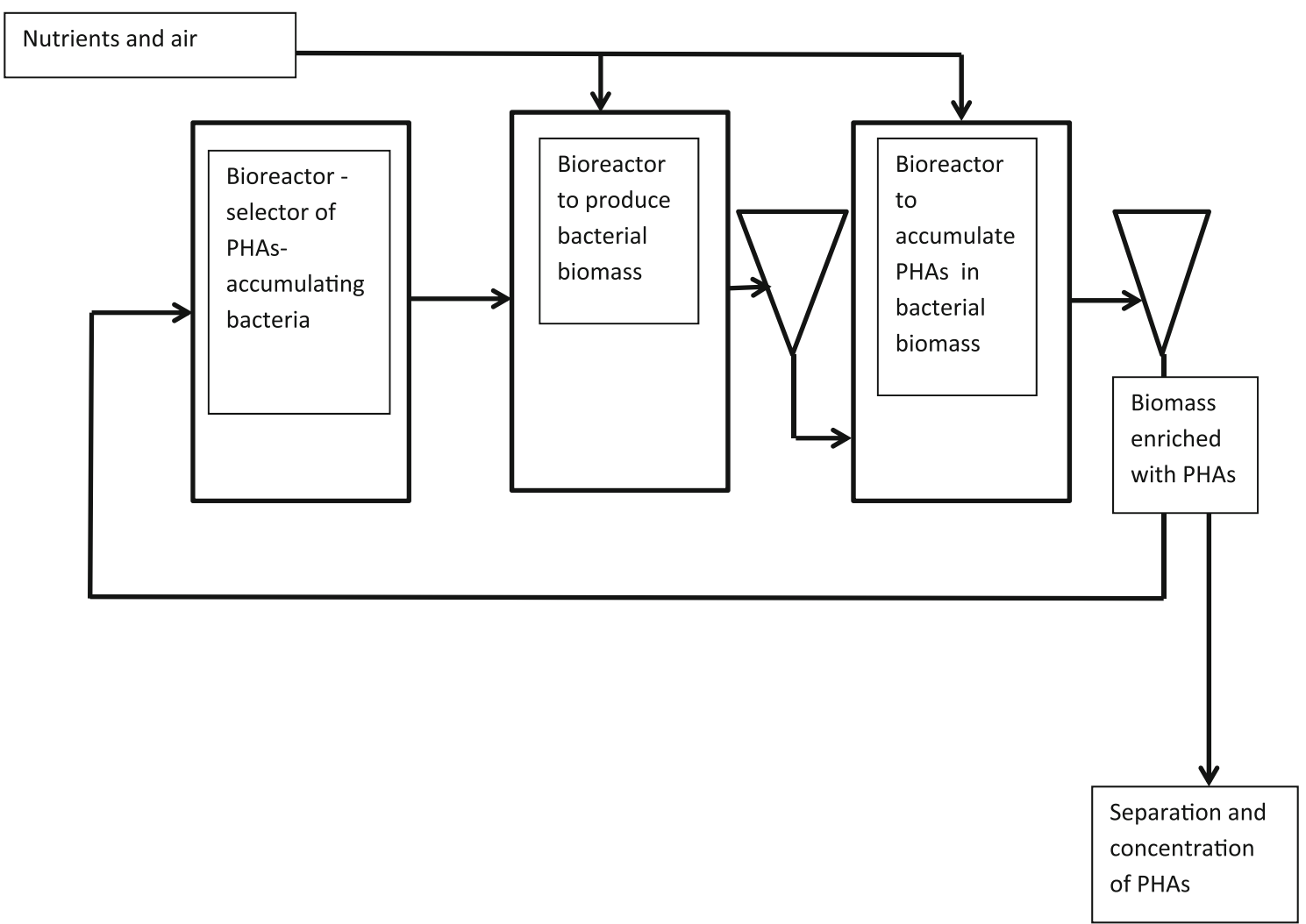

Fig. 5 Continuous production of PHAs with the selector

time for starvation, approximately from 2 to $20 \mathrm{~h}$, so cells with accumulated PHAs will grow and dominate in the microbial population, but cells without intracellular storage of PHAs will be suppressed in their growth or even die because of starvation. HRT in the bioreactor for the growth of biomass should be in the range from 1 to $20 \mathrm{~h}$, while HRT in the bioreactor for PHA accumulation should be several times longer.

The continuous systems of cultivation, for example a twostage chemostat with two reactors for the growth of bacteria and for the production of PHAs, showed the highest PHA accumulation (Ben Rebah et al. 2004). A batch process was used by Imperial Chemical Industry for the large-scale production of PHB. A continuous process was used by Austrian Company Chemie Linz GmbH for the pilot production of PHB. Productivity in the last case was about $1 \mathrm{~kg}$ of PHB/ day $/ \mathrm{m}^{3}$ of the bioreactor (Ben Rebah et al. 2004).

The PHA accumulation in the bacterial biomass, which is performed either in the second reactor of continuous system or on the second stage of batch process, can be initiated by two factors: (a) decrease in dissolved oxygen concentration lower $0.5 \mathrm{mg} / \mathrm{L}$ and (b) increase in concentration of VFA.

Another technological approach for the production of PHAs is semicontinuous cultivation of a mixed culture using a feast-famine cycle comprising a feast phase and a famine phase in one bioreactor. This cycling process promotes not only accumulation of PHAs in biomass but also selection of PHA-producing microorganisms (Salehizadeh and Van Loosdrecht 2004).

Batch production of PHAs

Batch biosynthesis of bioplastic is simpler but could be less productive than continuous process in the large-scale applications. At the first stage of batch process, a mixed culture is growing in a rich medium under intensive aeration and the optimal temperature and $\mathrm{pH}$ to ensure fast growth of microbial biomass with the highest growth yield. Essential nutrients, such as the sources of $\mathrm{N}$ or $\mathrm{P}$ are consumed during cultivation and accumulation of PHAs is started due to limitation of biomass growth by these nutrients but under excess of carbon source.

Growth of biomass must be performed at the concentrations of oxygen higher than $1 \mathrm{mg} / \mathrm{L}$. Using mixed culture, the growth parameters of conventional activated sludge can be used: $0.5 \mathrm{~g} \mathrm{BOD} / \mathrm{g}$ of dry biomass/day and $0.8 \mathrm{~g}$ of biomass/g of BOD consumed (Gray 2004), where BOD is "biological oxygen demand," i.e., oxygen used for bio-oxidation of the organic matter. So, to produce $1 \mathrm{~kg}$ of 
biomass in 10-L bioreactor with the maximum oxygen transfer rate $1 \mathrm{~g} / \mathrm{L} / \mathrm{h}$ (which is corresponding to biomass growth rate $0.8 \mathrm{~g}$ of dry bacterial biomass $/ \mathrm{L} / \mathrm{h}$ ), it is needed about 5 days. Considering that the content of PHAs in dry bacterial biomass will be accumulated to the level of $30 \%$, the maximum rate of PHA production in the mixed culture could be at the level about $0.24 \mathrm{~g}$ of dry PHAs/L/h. So, $1 \mathrm{~kg}$ of PHAs in 10-L bioreactor could be produced for about 17 days.

\section{Downstream processes}

Extraction and purification of PHAs

According to the present state of the art, PHA-containing biomass is processed: (1) by extraction of PHAs from dried biomass with organic solvents following the separation of solution by centrifugation or decantation; (2) cell walls and membranes are degraded chemically by oxidants and surfactants, and then, granules of PHAs are concentrated by centrifugation or flotation; (3) cell walls and membranes are degraded enzymatically, and then, granules of PHAs are concentrated by centrifugation or flotation; (4) cell walls and membranes of halophilic bacteria can be broken by osmotic shock (Selvakumar et al. 2011). Different methods for isolation and purification of bacterial PHAs were described in detail (Jacquel et al. 2008).

\section{Flotative separation of PHA granules}

A low-cost technology could be flotative separation of PHA granules from destroyed cells. The bubbles of air have the hydrophobic surface, so at the $\mathrm{pH}$ about 3.0-3.5, the difference in hydrophobicity of the surface of PHA granules and cell walls ensures the preferable adhesion of PHA granules to the air bubbles (Van Hee et al. 2006). This flotation is controlled by air bubbles, cells, and PHA granules interactions as well as flow rates of liquid and foam, sizes of the particles, hydrophobicity, and surface charge (zeta potential) depended on the pH. Finally, a PHA purity of $86 \%(\mathrm{w} / \mathrm{w})$ can be obtained using flotative separation and concentration of PHA granules (Van Hee et al. 2006). Simple flotative treatment is just supply of air in the flotation tank with bacterial suspension after cell disruption. It must be performed with the air bubbles of small diameter and intensive aeration to have the sufficient specific surface for PHA granule adhesion and a fast foam formation rate for its continuous removal. Additionally, for the effective batch or continuous flotation, there must be an automatic control of the level of liquid and the liquid supply rate, as well as the level of foam and the foam removal rate in the flotation tank to ensure proper separation of biomass and PHA granules.

The simpler and more reliable way for PHA granule separation and concentration is dissolved air flotation (DAF) in batch mode. Usually, it involves supply of compressed air into the tank with bacterial biomass for dissolved oxygen saturation at the excessive pressure, for example at $5 \mathrm{~atm}$, and then supply of this suspension to the flotation tank with the atmospheric pressure. The smallest air bubbles are releasing in the flotation tank due to the difference in gas solubility at the excessive or the atmospheric pressure. These small-sized air bubbles adsorb the most hydrophobic substances at their surfaces and float forming the foam. The foam, containing concentrated hydrophobic substances, is removed and collected. PHA granules are dried and then used as bioplastic. Many designs of DAF facilities for experimental and industrial applications are known.

\section{Crude PHA-containing bioplastic}

The major advantage of PHA-containing bioplastic for applications is biodegradability of this bioplastic by soil and aquatic microorganisms. These microorganisms produce PHA depolymerases and other enzymes and finally transform PHA-made items to carbon dioxide and water for about 1.5 months in anaerobic sewage, 1.5 years in soil, and 6.5 years in seawater (Castilho et al. 2009; Mergaert et al. 1992). Bacterial biomass with accumulated PHA granules contains also polysaccharides of cell wall, proteins, polynucleotides, and phospholipids, where the contents are about $15,50,25$, and $10 \%$ of dry biomass without PHAs, respectively, and the biodegradation rates are higher than those of PHAs. Therefore, from the point of view of biodegradability in soil, there is no sense to extract PHAs from biomass but to use dry biomass with accumulated inside PHA granules as crude bioplastic. This crude PHA-containing bioplastic is a nanocomposite comprising of the PHA granules and interlayers of cellular biopolymers. Hypothetically, such nanocomposite should be more flexible and faster biodegradable than extracted PHAs. Many natural biocomposites are known, where brittle nanocomponent like hydroxyapatite crystals in the bone or aragonite crystals in the pearls are composed of flexible biopolymer nanocomponents, usually nanolayers or nanoaggregates of protein molecules. Production of the similar nanocomposite material from PHA-containing dry bacterial biomass will permit to exclude the stage of PHA extraction and diminish the cost of crude PHA-containing biodegradable material. 


\section{Crude PHA-containing bioplastic for construction and agricultural applications}

\section{Market for PHA-containing crude bioplastic}

Potential market of bioplastics includes packaging materials, catering products, consumer electronics, medical materials, agriculture and horticulture (biodegradable mulch foil), toys, textiles (Du et al. 2012). Past and present industrial production of PHA-containing bioplastic is mainly for medical applications such as skin substitutes, heart valves, vascular grafts, scaffolds, bone graft substitutes, and drug delivery microspheres because of PHA biocompatibility and biodegradability (Chen et al. 2005). Application of PHA-containing bioplastic for the manufacturing of low-volume and high-cost biomedical items is becoming a reality, but even for these applications, there must be developed more efficient and economical processes for the PHA production, isolation, purification, and improvement in PHA material properties (Keshavarz and Roy 2010).

However, PHA-containing bioplastic, which is produced by non-aseptic cultivation of mixed bacterial cultures from waste materials, cannot be used for biomedical, food packaging, or catering applications because chemical and physical properties of PHA-containing bioplastic are not controlled in non-aseptic cultivation, and there may be a lot of pollutants in the product that were released from MSW and microorganisms.

The type of application depends also on the mechanical properties of bioplastic. PHA mechanical properties depend very significantly on the chain length of the monomer. For example, PHB is stiffer and more brittle than for polypropylene, but copolymerization with hydroxyvalerate (PHB-co-PHV) makes bioplastic much more flexible (Castilho et al. 2009). This copolymer can be used for packaging material like films and bottles (Ben Rebah et al. 2004). However, PHB applications are limited by its thermal degradation during molding and stiffness of bioplastic. For aseptic cultivation of genetically modified strains of PHA producers is it possible to select specific medium and conditions for the production of PHAs with the desired mechanical properties, but for non-aseptic cultivation of mixed culture, the chemical content of accumulated PHAs will be determined mainly by the spectrum of fatty acids in the medium.

\section{Properties of crude PHA-containing bioplastic}

There are two potential problems in the applications of crude PHA-containing nanocomposite bioplastic. First problem is the high temperature of PHA melting, which is in the range $160-180{ }^{\circ} \mathrm{C}$ (Castilho et al. 2009; Sudesh and Abe 2010; Volova 2004). Melting temperature of PHB is close to its thermal decomposition temperature $T_{\mathrm{d}}$ (Chen and Lo 2012). Thermal decomposition temperatures of proteins, polysaccharides, and polynucleotides are also close to this value, i.e., all biopolymers have poor thermal stability at the temperature of PHA melting. Natural antioxidants, which present in biomass, can reduce the rate of thermal destruction of biopolymers (Giner et al. 2012). Protein itself can be considered as the thermoplastic material but with addition of plasticizers, which inhibit the formation of cross-linking that can result in the formation of the thermoset material from extruded protein (Verbeek and van den Berg 2009). Therefore, the molding of composite crude PHA-containing bioplastic must be as short as possible to diminish the thermal decomposition of PHAs and other biopolymers of bacterial biomass.

Potential applications of bioplastic in the construction industry

The construction industry is exhibiting a trend toward the use of biodegradable materials and biopolymers (Plank 2004; Ramesh et al. 2010). Traditionally, almost all construction activities utilize wood and other cellulose-containing natural materials, the most abundant of biodegradable polymeric materials. However, these traditional materials decompose at a relatively slow rate, resulting in an increased demand for areas to be used for landfill purposes. Increasing the utilization of PHAs in the construction would help alleviate this ultimately unsustainable practice, thereby reclaiming land for commercial or residential development.

Plastic foam and foam insulators that are used in the construction industry produce hazardous non-biodegradable waste after demolition of buildings or temporary constructions. Sustainable, biodegradable PHA-containing bioplastic foam can be used for insulation walls and partitions and construction of non-structural (internal) elements such as separating walls and partitions for temporary constructions. The PHA-containing bioplastic foam would be an innovative and environmentally green, sustainable construction material that would degrade quickly being landfilled or could alternatively be composted.

Other potential applications of crude nanocomposite from bacterial biomass containing PHAs include construction silt and dust fences that can be landfilled for fast biodegradation or composted as biomass. Sustainability of biodegradable construction materials is due to (1) the production of bioplastic from renewable sources or even from organic waste and (2) fast biodegradability of this material under landfill conditions or composting to minimize the negative environmental impact of construction 
waste. In addition, biodegradable bioplastic foam construction material would be highly marketable because it does not require incineration after demolition.

Potential applications of bioplastic in agriculture

Agriculture is another highly potential market for applications of nanocomposite bioplastic from bacterial biomass containing PHAs. One potential application is the replacement of dark plastic mulch, which is currently used to suppress weeds, reduce water evaporation from soil, and warm soil for earlier planting. Millions of hectares of arable land are cultivated under plastic mulch. However, non-biodegradable plastic mulch requires labor-intensive annual removal from the field for disposal or energy-consuming and environmentally unfriendly recycling of the used film. The advantage of utilizing film from nanocomposite bioplastic from bacterial biomass containing PHAs is that it can provide all of the benefits of traditional plastic mulch but can be left in place for natural biodegradation on the field. Another agricultural application of nanocomposite bioplastic from bacterial biomass with PHAs is manufacturing of slow-release fertilizers using bioplastic coating or embedding of fertilizers in bioplastic granules, bars, or films. For example, fertilizer embedded in bioplastic bars can be used on oil palm plantations as timereleased fertilizers as the bioplastic degrades over a $0.5-2-$ year time period.

\section{Conclusion}

The production of low-cost crude bioplastic is possible by mixed microbial cultures under non-aseptic conditions of cultivation. Organic acids produced by acidogenic fermentation of solid municipal waste can be the dominating source of carbon for the biosynthesis of crude bioplastic. The environmental benefits from the production and the use of crude bioplastic from the organic fraction of solid municipal waste include (1) reduction in the amount of MSW to be incinerated; (2) reduction in the amount of ash to be landfilled; and (3) use of seawater for MSW separation, which will conserve freshwater resources. Crude PHA-containing bioplastic can be used for several applications in both construction and agricultural industries. In the construction industry, PHAcontaining bioplastic foam could be used in the manufacture of foam insulators, silt, and dust fence insulation of walls and partitions, construction of non-structural elements such as separating walls and partitions and temporary constructions. Applications of PHA-containing bioplastic in the agriculture include the replacement of traditional dark plastic mulch and different carriers for time-release fertilizers.

Acknowledgments The studies presented in this paper were supported by Nanyang Technological University, Singapore; National University of Food Technologies, Kiev, Ukraine; King Abdulaziz University, Jeddah, Kingdom of Saudi Arabia; Iowa State University of Science and Technology, Ames, USA; and ASA Institute, Brooklyn, USA.

\section{References}

Abd-El-Haleem D, Amara A, Zaki S, Abulhamd A, Abulreesh G (2007) Biosynthesis of biodegradable polyhydroxyalkanotes biopolymers in genetically modified yeasts. Int J Environ Sci Technol 4:513-520

Abouelenien F, Fujiwara W, Namba Y, Kosseva M, Nishio N, Nakashimada Y (2010) Improved methane fermentation of chicken manure via ammonia removal by biogas recycle. Bioresour Technol 101:6368-6373

Barlaz MA, Staley BF, De Los Reyes FL III (2010) Anaerobic biodegradation of solid waste. In: Mitchell R, Gu JD (eds) Environmental microbiology, 2nd edn. Wiley, Hoboken, pp 281-299

Ben Rebah F, Yan S, Filali-Meknassi Y, Tyagi RD, Surampalli RY (2004) Bacterial production of bioplastics. In: Surampalli RY, Tyagi RD (eds) Advances in water and wastewater treatment. ASCE Publications, pp 42-71

Bolzonella D, Fatone F, Pavan P, Cecchi F (2005) Anaerobic fermentation of organic municipal solid wastes for the production of soluble organic compounds. Ind Eng Chem Res 44:3412-3418

Braun R, Drosg B, Bochmann G, Weiss S, Kirchmayr R (2010) Recent developments in bio-energy recovery through fermentation. In: Insam H, Franke-Whittle I, Goberna M (eds) Microbes at work, from waste to resources. Springer, Berlin, pp 35-58

Buathong S, Chiemchaisri C, Chiemchaisri W, Hiroyasu Satoh H (2012) Polyhydroxyalkanoate (PHA) production potential of activated sludge from food industrial wastewater treatment process. Int J Environ Eng 4:210-219

Castilho LR, Mitchell DA, Freire DMG (2009) Production of polyhydroxyalkanoates (PHAs) from waste materials and byproducts by submerged and solid-state fermentation. Bioresour Technol 100:5996-6009

Cesaro A, Belgiorno V, Naddeo V (2011) Comparative technology assessment of anaerobic digestion of organic fraction of MSW. In: Brebbia CA (ed) The sustainable world. Wessex Institute of Technology, Ashurst, pp 355-366

Chen BK, Lo SH (2012) Thermally stable biopolymer for tissue scaffolds. Plastic research online. Soc Plast Eng. doi:10.2417/ spepro.004171, http://www.4spepro.org

Chen GQ, Wu Q, Wang Y, Zheng Z (2005) Application of microbial polyesters-polyhydroxyalkanoates as tissue engineering materials. Key Eng Mater 288-289:437-440

Choi D, Chipman D, Bents S, Brown R (2010) A techno-economic analysis of polyhydroxyalkanoates and hydrogen production from syngas fermentation of gasified biomass. Appl Biochem Biotechnol 160:1032-1046

Dobrenko S, Joarder M (2011) Business aspects of municipal solid waste and technology of hydroseparation in the USA. J Bus Glob 2:25-38

Dobrenko S, Maksimov V, Pryakhin V, Lazarenko M (2012) Comparative analysis of aero- and hydroseparation of municipal 
solid waste. In: Proceedings international conference. The role of water reclamation in the innovative development of agriculture, Moscow, pp 22-32

Du C, Sabirova J, Soetaert W, Lin SKC (2012) Polyhydroxyalkanoates production from low-cost sustainable raw materials. Curr Chem Biol 6:14-25

Giner JME, Boronat T, Balart R, Fages E, Moriana R (2012) Antioxidant effects of natural compounds on green composite materials. Plastic research online. Soc Plast Eng. doi:10.2417/ spepro.004379, http://www.4spepro.org

Gray NF (2004) Biology of wastewater treatment. Imperial College Press, London

Gumel AM, Annuar MSM, Heidelberg T (2012) Biosynthesis and characterization of polyhydroxyalkanoates copolymers produced by Pseudomonas putida bet001 isolated from palm oil mill effluent. PLoS ONE 7:e45214. doi:10.1371/journal.pone.0045214

Ivanov V (2010) Environmental microbiology for engineers. CRC Press, Boca Raton

Ivanov V, Chu J (2008) Applications of microorganisms to geotechnical engineering for bioclogging and biocementation of soil in situ. Rev Environ Sci Biotechnol 7:139-153

Ivanov VN, Stabnikova EV, Stabnikov VP, Kim IS, Zubair A (2002) Effects of iron compounds on the treatment of fat-containing wastewaters. Appl Biochem Microbiol 38:255-258

Jacquel N, Lo CW, Wei YH, Wu HS, Wang SS (2008) Isolation and purification of bacterial poly(3-hydroxyalkanoates). Biochem Eng J 39:15-27

Kelleher M (2007) Anaerobic digestion outlook for MSW streams. BioCycle 48:51-55

Keshavarz T, Roy I (2010) Polyhydroxyalkanoates: bioplastics with a green agenda. Curr Opin Microbiol 13:321-326

Lei X, Sugiura N, Feng C, Maekawa T (2007) Pretreatment of anaerobic digestion effluent with ammonia stripping and biogas purification. J Hazard Mater 145:391-397

Lenz RW, Marchessault RH (2005) Bacterial polyesters: biosynthesis, biodegradable plastics and biotechnology. Biomacromolecules $6: 1-8$

Lu Y (2007) Advance on the production of polyhydroxyalkanoates by mixed cultures. Front Biol China 2:1673-3509

Lynd LR, Weimer PJ, van Zyl WH, Pretorius IS (2002) Microbial cellulose utilization: fundamentals and biotechnology. Microbiol Mol Biol Rev 66:506-577

Macias-Corral M, Samani Z, Hanson A (2008) Anaerobic digestion of municipal solid waste and agricultural waste and the effect of codigestion with dairy cow manure. Bioresour Technol 99:8288-8293

Madigan MT, Martinko JM, Stahl D, David P, Clark DP (2012) Brock biology of microorganisms, 13th edn. Pearson, London

Maness PC, Weaver PF (1994) Production of poly-3-hydroxyalkanoates from $\mathrm{CO}$ and $\mathrm{H}_{2}$ by a novel photosynthetic bacterium. Appl Biochem Biotechnol 45(46):395-406

Md Din MF, Ponraj M, van Loosdrecht MCM, Ujang Z, Chelliapan S, Zambare V (2013) The utilization of palm oil mill effluent for polyhydroxyalkanoate production and nutrient removal using statistical design. Int J Environ Sci Techno. doi:10.1007_s13762013-0253-9

Mergaert J, Anderson C, Wouters A, Swings J, Kerster K (1992) Biodegradation of polyhydroxyalkanoates. FEMS Microbiol Rev 103:317-322

Mokhtarani N, Ganjidoust H, Farahani EV (2012) Effect of process variables on the production of polyhydroxyalkanoates by activated sludge. Iran J Environ Health Sci Eng. doi:10.1186/ 1735-2746-9-6

Mudhoo A, Kumar S (2013) Effects of heavy metals as stress factors on anaerobic digestion processes and biogas production from biomass. Int J Environ Sci Technol 10:1383-1398. doi:10.1007/ s13762-012-0167-y

O'Flaherty V, Collins G, Mahony T (2010) Anaerobic digestion of agricultural residues. In: Mitchell R, Gu JD (eds) Environmental microbiology, 2nd edn. Wiley, Hoboken, pp 259-279

Palmeri R, Pappalardo F, Fragala M, Tomasello M, Damigella A, Catara AF (2012) Polyhydroxyalkanoates (PHAs) production through conversion of glycerol by selected strains of Pseudomonas mediterranea and Pseudomonas corrugata. Chem Engrg Transactions 27:121-126. doi:10.3303/CET1227021

Plank J (2004) Application of biopolymers and other biotechnological products in building materials. Appl Microbiol Biotechnol 66:1-9

Preethi R, Sasikala P, Aravind J (2012) Microbial production of polyhydroxyalkanoate (PHA) utilizing fruit waste as a substrate. Res Biotech 3:61-69

Rahman MO, Hussain A, Basri H (2013) A critical review on waste paper sorting techniques. Int J Environ Sci Technol. doi:10.1007/ s13763-013-0223-3

Ramesh BNG, Anitha N, Rani HKR (2010) Recent trends in biodegradable products from biopolymers. Adv Biotech 9:30-34

Salehizadeh H, Van Loosdrecht MCM (2004) Production of polyhydroxyalkanoates by mixed culture: recent trends and biotechnological importance. Biotechnol Adv 22:261-279

Sandhya M, Aravind J, Kanmani P (2013) Production of polyhydroxyalkanoates from Ralstonia eutropha using paddy straw as cheap substrate. Int J Environ Sci Technol 10:47-54

Selvakumar K, Srinivasan G, Baskar V, Madhan R (2011) Production and isolation of polyhydroxyalkanoates from Haloarcula marismortui MTCC 1596 using cost effective osmotic lysis methodology. Eur J Exp Biol 1:180-187

Serafim LS, Lemos PC, Albuquerque MGE, Reis MAM (2008) Strategies for PHA production by mixed cultures and renewable waste materials. Appl Microbiol Biotechnol 81:615-628

Stabnikov VP, Ivanov VN (2006) The effect of iron hydroxide concentrations on the anaerobic fermentation of sulfate-containing model wastewater. Appl Biochem Microbiol 42:284-288

Strauber H, Schroder M, Kleinsteuber S (2012) Metabolic and microbial community dynamics during the hydrolytic and acidogenic fermentation in a leach-bed process. Energy Sustain Soc 2:13

Sudesh K (2013) Polyhydroxyalkanoates from palm oil: biodegradable plastics. Springer, Heidelberg, p 130

Sudesh K, Abe H (2010) Practical guide to microbial polyhydroxyalkanoates. Smithers Rapra Technology, Shrewsbury, p 160

US EPA (2011) Municipal solid waste generation, recycling, and disposal in the United States: Facts and figures for 2010. http:// www.epa.gov/epawaste/nonhaz/municipal/pubs/2010_MSW_ Tables_and_Figures_508

Van Hee P, Elumbaring CMRA, Van der Lans RGJM, Van der Wielen LAM (2006) Selective recovery of polyhydroxyalkanoate inclusion bodies from fermentation broth by dissolved-air flotation. J Coll Interface Sci 297:595-606

Verbeek CJR, van den Berg LE (2009) Extrusion processing and properties of protein-based thermoplastics. Macromol Mater Eng. doi:10.1002/mame.200900167

Vishnuvardhan RS, Thirumala M (2012) Isolation of polyhydroxyalkanoates (PHA) producing bacteria from contaminated soils. Int J Environ Biol 2:104-107

Volova TG (2004) Polyhydroxyalkanoates-plastic materials of the 21st century. Nova Publishers, Hauppauge

Wang YS, Odle W, Eleazer WE, Barlaz MA (1997) Methane potential of food waste and anaerobic toxicity of leachate produced during food waste decomposition. Waste Manag Res 15:149-167 
Yee LN, Mumtaz T, Mohammadi M, Phang LY, Ando Y, Raha AR, Sudesh K, Ariffin H, Hassan MA, Zakaria MR (2012) Polyhydroxyalkanoate synthesis by recombinant Escherichia coli JM109 expressing PHA biosynthesis genes from Comamonas sp. EB172. Microb Biochem Technol 4:103-110
Yu J (2006) Production of biodegradable thermoplastic materials from organic wastes. US Patent 7,141,400. November 28, 2006 